\title{
Análise do valor na conformação de tailored-blanks
}

\author{
Ronnie Peterson Schröder Volkwagen do Brasil Ltda. \\ Paulo Victor Prestes Marcondes UFPR
}

\section{RESUMO}

Uma forma encontrada na indústria automobilística de reduzir os consumos associados à fabricação é a utilização de chapas de diferentes espessuras soldadas a laser. Essas chapas são comercialmente denominadas de tailored blanks, onde os principais objetivos são as reduções do peso e do custo final do produto. As abordagens da análise do valor em tailored blanks se tornam cada vez mais adequada visto esta ser uma tecnologia cada vez mais usada na produção de veículos. A peça em estudo foi o reforço interno da porta dianteira de um veículo quatro portas nacional. $\mathrm{O}$ objetivo deste trabalho foi à utilização da metodologia da Análise do Valor, na obtenção de resultados financeiros que possam tornar o produto mais competitivo, segundo a análise das funções do produto. Como resultado destaca-se que o custo no Brasil da utilização de tailored blanks, para a peça de tamanho médio que foi estudada em 2004, mostrou-se financeiramente inviável. O custo de manufatura por estampagem é muito superior à economia gerada pela redução de consumo da matéria-prima.

\section{PALAVRAS-CHAVE}

Análise do valor, chapas soldadas a laser, estampagem.

\section{Analysis of the value on forming of tailored blanks}

\begin{abstract}
Nowadays, the automobile industry is using blanks with different thickness denominated tailored blanks. The main objectives are the reduction of the weight and of the final cost of the product. The use of tailored blanks is a technology more and more used in the vehicle production. The Analyses of the Value approaches in the tailored blanks technology used in automobile industry are becoming even more adequate. The studied product was the internal front door reinforcement of a four doors national vehicle. The objective of this work was the use of the Analysis of the Value methodology in order to obtain financial results that can propitiate a more competitive product, according to the analysis product functions. The results showed that the tailored blank cost in Brazil is financially unviable for the medium piece that was studied in 2004. The manufacture cost is very superior in relation to the economy generated by the raw material consumption reduction.
\end{abstract}

\section{KEY WORDS}

Analysis of the value, tailored blanks, deep drawing. 


\section{INTRODUÇÃO}

As vantagens da soldagem a laser resultam da alta flexibilidade do processo, da inexistência de contato com a peça e soldas de qualidade com altas velocidades. Outros benefícios incluem o fato da quase inexistência de retrabalho. $\mathrm{O}$ processo de soldagem a laser também permite soldar de um só lado, o que propicia novas soluções em projetos. Devido à qualidade da radiação laser, sua utilização em soldagem possibilita a obtenção de determinadas características praticamente impossíveis de serem obtidas por outros processos, tais como baixo aporte térmico, pouca distorção e pequenas zonas afetadas pelo calor. $\mathrm{O}$ interesse na soldagem a laser de chapas metálicas tem aumentado consideravelmente, devido a apresentar um alto potencial de redução de custos (DI PIETRO, 1992).

\section{Ima forma encontrada na indústria automobilística de reduzir consumos é a utilização de chapas de diferentes espessuras soldadas a laser.}

A Contabilidade de Custos que, ao longo do tempo, já deixara de ter a mera função de avaliar os estoques, passou a assumir outras atribuições de caráter administrativo. Isto se deu com a introdução de técnicas já conhecidas como JIT (Técnica que procura eliminar todas as fontes de desperdício em atividades produtoras, colocando o componente certo no lugar certo e na hora certa), TQC (Controle Total da Qualidade, técnica que compreende as atividades de controle em todas as fases das quais depende a satisfação do cliente), $\mathrm{ABC}$ (Ferramenta gerencial que permite identificar quais itens justificam atenção e tratamento adequados quanto à sua importância relativa, através da divisão em 3 classes distintas) e a Análise do Valor (técnica que será abordada no presente trabalho).

Nakagawa (1991), diz que as premissas que são inteligentemente adotadas para o êxito de qualquer empreendimento consistem basicamente em buscar o mercado certo, empregar corretamente os recursos disponíveis (materiais, humanos e financeiros), adotar a tecnologia recomendável e praticar os processos administrativos adequados.

Leone (2000), mostra que para atingir padrões ideais de competitividade devido à otimização da qualidade e conseqüentemente da produtividade, a tarefa será grandemente facilitada, com as informações gerenciais recebidas pela Contabilidade de Custos. É útil não esquecer naturalmente da contribuição de outras ciências, que estarão auxiliando a tarefa do Contador de Custos na busca da realização cor- reta dos seus propósitos. Em economias não-competitivas, o preço final do produto é fixado em função do custo de produção e do volume vendido, fixando-se o lucro esperado. Em economias competitivas, a tendência é reconhecer que o preço unitário é influenciado pelo mercado, e que a forma de aumentar a margem de lucro unitário é reduzir o custo de produção. Para se aumentar o lucro total, deve-se aumentar o volume de vendas. Mas a demanda é fortemente afetada pela qualidade e pelo preço final do produto (PETENATE, 2001).

Firjan (2002) descreve a importância de conhecermos bem o negócio e seus problemas, pois seria de baixo proveito possuir um profundo conhecimento da utilização das ferramentas, sem termos uma adequada caracterização da situação que nos é entregue para solução. Em outras palavras, a melhor solução é a que for obtida pelo binômio do conhecimento qualidade-negócio, ou seja, a competitividade. Assim, a Contabilidade de Custos passou a oferecer elementos de medição e análise para alcançar objetivos administrativos e econômicos, além dos financeiros. Com a sua utilização, as informações significativas para a gestão dos negócios da empresa, em ambientes de maior competitividade, permitem perseguir índices mais elevados de produtividade e qualidade, com conseqüente redução de desperdícios, inclusive o tempo ocioso de máquinas e pessoal (BIO, 1991).

A Análise do Valor é uma metodologia que visa obter um custo mínimo para a realização de uma determinada função. Visa identificar a melhor relação entre qualidade, desempenho das funções e custos de um determinado produto. Pode ser definido ainda como um esforço organizado, dirigido para analisar as funções de bens e serviços para atingir funções necessárias e características essenciais da maneira mais rentável (CSILLAG, 1995).

Cheah (2005) introduz que a Análise do Valor teve origem durante a Segunda Guerra Mundial, como resultado da aplicação de conceitos desenvolvidos por Miles (1972) que na época era Engenheiro do Departamento de Compras da General Electric Co. Existem algumas técnicas e procedimentos para determinar o valor que é dado para as funções dos componentes as quais podem variar com o tipo de agrupamento usado. Porém, os agrupamentos normalmente incluem: a análise do projeto de toda a manufatura, quadro de análise dos componentes, uma revisão de outras organizações com experiências similares, sessão de brainstorming, análise do custo funcional, revisão dos fornecedores e atualização e conclusão e finalmente o relatório (ZENS, 1994). 
Fleming (1992) mostra que o valor agregado tem como foco a relação entre os custos reais incorridos e o trabalho realizado no projeto dentro de um determinado período de tempo. O foco no desempenho obtido em comparação com o que foi gasto para obtê-lo. Podem ser citados vários exemplos de trabalho que não agregam valor aos produtos, tais como excesso de movimentação, retrabalho, etc., estas operações devem ser reduzidas ou eliminadas. $\mathrm{Na}$ busca de redução de custo, Forgart at alli, (1991) sugeriram como uma função do comprador a análise inicial dos valores, devido ao alto custo dos produtos comprados. Neste contexto, o objetivo da Análise do Valor é identificar a alternativa com o menor custo, mantendo as especificações do produto a ser comprado. Porém, a Análise do Valor, está além das funções do departamento de compras, abordagem esta que será mostrada neste trabalho com a criação de um time multifuncional na análise de todo o processo.

Vargas (2002) mostra passos importantes para o estímulo ao sucesso de um projeto no âmbito técnico, organizacional e até mesmo comportamental na criação de um time multifuncional que abordará análise do valor em produtos ou serviços dentro de uma empresa.

A metodologia para aplicação do método de Análise do Valor. Conhecendo os conceitos de valor e funções e entendendo a análise como a decomposição de algo em partes para realização de um exame, o conceito de Análise do Valor consiste em decompor o produto ou serviço em funções, examinando-se o valor de cada uma das funções. A questão que se apresenta é qual a base de valor na qual as funções serão examinadas. Sabendo que: Valor = Função/Custo, então para a Análise do Valor, como uma função pode ser realizada de várias formas, a mais relevante será realizá-la da melhor maneira e com o menor custo.

O usuário analisará o desempenho de cada função, podendo levar em conta fatores como a comparação com produtos concorrentes, a qualidade, as diferenças no preço, a necessidade de novos produtos, as qualidades da distribuição, a campanha promocional, a qualidade na pósvenda, o treinamento dos vendedores, a garantia, a imagem, etc. Já do ponto de vista do produtor, o valor do produto será a relação de quanto a função custa para ser fabricada, ou seja, quanto menor o custo maior o valor (HAMILTON, 2002). Havendo mais de um produto, seu valor será dado pelo máximo lucro que o mesmo poderá retirar de sua produção, considerando uma determinada capacidade produtiva global e a utilização relativa que o produto faz dessa capacidade produtiva.
Miles (1972) criou o plano de trabalho para servir como instrumento sistemático da metodologia. Mesmo considerando sua flexibilidade e que este plano tenha sido modificado por outros pesquisadores e possa sofrer adequação em suas etapas, que podem ser repetidas ou alteradas, conforme as circunstâncias temporais e locais, o referido plano veio tornar o uso prático da metodologia mais acessível. Pereira Filho (1994) faz uma explanação bastante abrangente de cada etapa e cada passo a ser seguido, clareando as dúvidas e eliminando as dificuldades que porventura surjam.

\section{A análise de Valor é uma metodologia que visa uma determinada função.}

O plano de trabalho idealizado por Miles constituía-se de: fase da orientação, fase da informação, fase da especulação ou criatividade, fase da análise, fase de planejamento do programa, fase de proposta do programa, fase de resumo e conclusões.

No Brasil, a partir de 1970, grandes empresas vêm se utilizando dessa metodologia, destacando-se algumas como:

- Volkswagen, Mercedes Benz, Petrobras, Kablin do Paraná, TRW, FIAT, Multibras, BASF, IBM, General Motors (ABEAVE, 1984).

Com a finalidade de divulgar essa técnica também no Brasil, foi fundada em julho de 1984 a ABEAV - Associação Brasileira de Engenharia e Análise do Valor. Outras associações também trabalham na divulgação dessa metodologia, que são a SJVE - Sociedade Japonesa de Engenheiros do Valor fundada em 1985, e a AFAV - Associação Francesa de Análise do Valor, fundada em 1978.

Segundo a Sociedade Americana de Engenheiros de Valor (SAVE), a Análise do Valor "é uma aplicação sistemática de técnicas reconhecidas que identificam a função de um produto ou serviço, estabelecendo um valor monetário para cada função e provendo as funções com a confiabilidade necessária ao menor custo total" (CSILLAG, 1991). O objetivo geral deste trabalho foi a utilização da metodologia da Análise do Valor, na obtenção de resultados financeiros que possam tornar o produto fornecido mais competitivo, segundo a análise das funções do produto, seja ele primário ou secundário, do ponto de vista do consumidor, apresentando propostas adaptadas para o caso, considerando as particularidades do processo produtivo como um todo. 


\section{PROCEDIMENTO EXPERIMENTAL}

Foram efetuadas análises financeiras, como análise dos estoques por peso, pelo custo e por dias de produção, análise de custo da matéria-prima para o processo atual e para as propostas a serem apresentadas, para os custos logísticos de transporte, ou seja, para todos os processos envolvidos na fabricação do item em estudo (SCHRÖDER, 2004).

O resultado do projeto foi obter a maior quantidade de informações possíveis, tanto financeiras como de processos, para o auxílio na formação de um quadro que possa mostrar as alternativas sugeridas com as respectivas influências na alteração do projeto, produto, processos e custos. Neste trabalho, foi utilizado o modelo da Figura 1.

Planejamento da fase de orientação. Esta fase constitui-se de quatro passos básicos:

1. O primeiro passo é a definição ou seleção do objeto a ser estudado. Para a escolha do item a ser submetido à análise, pode-se partir de: uma exigência legal, da sugestão de uma auditoria, da posição competitiva do produto, da dependência de materiais escassos, da redução de custos, entre outros fatores. A importância da definição do objeto a ser estudado encontra-se no fato de que dele dependerá desde já o direcionamento do trabalho e dos resultados.

2. O segundo passo é a determinação do objetivo, que leva- rá os resultados a uma ordem econômica ou técnica, ou ambas, conforme a necessidade que originou o trabalho. Para esta pesquisa, em que se busca investigar os custos ambientais, se sobressai à ordem econômica.

3. No terceiro passo, que é a formação do grupo de trabalho, tem-se a constatação da multidisciplinaridade trabalhada pela metodologia (equipe formada por pessoas das diversas áreas da organização, onde cada membro traz para o grupo a visão do objeto a ser analisado conforme a construção dos seus conhecimentos). O grupo pode ser constituído através de convite ou indicação das pessoas envolvidas ou interessadas no assunto.

4. Nesta fase, devemos responder às seguintes questões:

a) O que deve ser desempenhado?

b) Quais os desejos e as necessidades reais deste estudo?

c) Quais são as características e propriedades desejadas quanto ao peso, às dimensões, à aparência, à vida desejada etc.?

Nesta fase, foi feita a seleção do objeto para o estudo. Após a seleção do objeto, foi feito todo planejamento das determinações do objetivo, ou seja, foram mostrados os meios pelos quais se buscou a informação para a orientação que ajudará na fase da informação e da análise.

Seleção do objeto. O objeto selecionado é formado por três chapas, ou platinas, de espessuras diferentes, que após a soldagem a laser, são conformadas por embutimento obtendo-se assim o produto final que é o reforço interno da

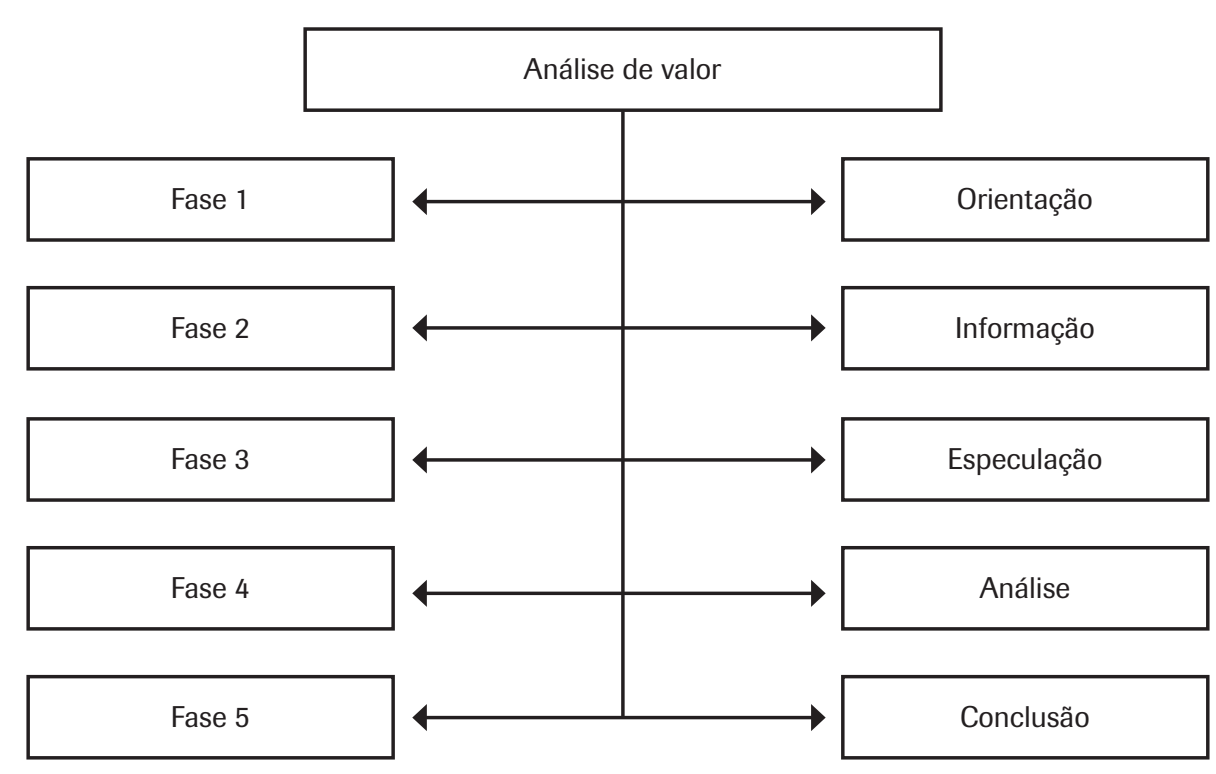

Figura 1: Modelo proposto para o estudo de caso. 
porta dianteira de um veículo produzido nacionalmente, como pode ser visto na Figura 2.

Determinação do objetivo. O objetivo foi avaliar três alternativas diferentes para o processo atual junto com as influências e a realização de análises financeiras em todos os aspectos possíveis relacionados ao produto. Análises financeiras que foram abordadas com maior profundidade: custo da matéria-prima, custo do inventário, custo de manufatura da chapa a ser conformada e custos logísticos. Análises de processos que foram abordados com maior profundidade: movimentações, controle de inventário, planejamento da solicitação da matéria-prima, peso inicial (chapa cortada), peso final (peça conformada) e produtividade (golpes por minuto da peça conformada).

Entrevista com as áreas envolvidas. Procura de informações junto à engenharia de produto, manufatura e processos, compras, logística, finanças, qualidade e fornecedor do tailored blank:

- Engenharia do produto - características do material, plano de corte, normas e funções a serem consideradas na abordagem da nova proposta;

- Engenharia de manufatura - produtividade e planejamento de produção;

- Engenharia de processo - modificações do ferramental;

- Compras - negociações e controle de pedidos;

- Logística - planejamento de liberação de pedido;

- Finanças - conhecimento técnico de custo logístico e contabilidade de custo;

- Industrializador - processo atual para a manufatura do tailored blank, $\mathrm{e}$

- Usina - distâncias em relação ao industrializador, planta de consumo e entre industrializador da proposta.

Planejamento da fase de informação. Esta fase no plano de trabalho da Análise do Valor tem por finalidade o conhecimento da situação atual, por parte do grupo de trabalho. É através desta fase que o grupo terá uma compreensão total do problema que está sendo analisado.

Na fase de informação devemos: Obter as informações gerais sobre o objeto de análise, Descrever e Classificar as Funções.

Pode parecer difícil e cansativa a consecução desses passos, porém dela dependerá a exatidão com a qual o estudo prosseguirá.

Nesta fase, será feita a coleta de todos os fatos e informações disponíveis sobre: custos, quantidade, fornecedores, investimentos, métodos de manufatura, informação sobre o mercado fornecedor, controle de qualidade, embalagem etc. Será feita uma estimativa da quantia que poderá ser razoavelmente gasta em cada um dos fatores em vista das quantidades, custos e outros fatos pertinentes. As funções serão estabelecidas, definidas e avaliadas. Ainda nesta fase, será determinada a função secundária. As perguntas que devem ser respondidas nesta fase são:
a) Qual a função principal?
b) Qual a função secundária?
c) Qual o custo atual?

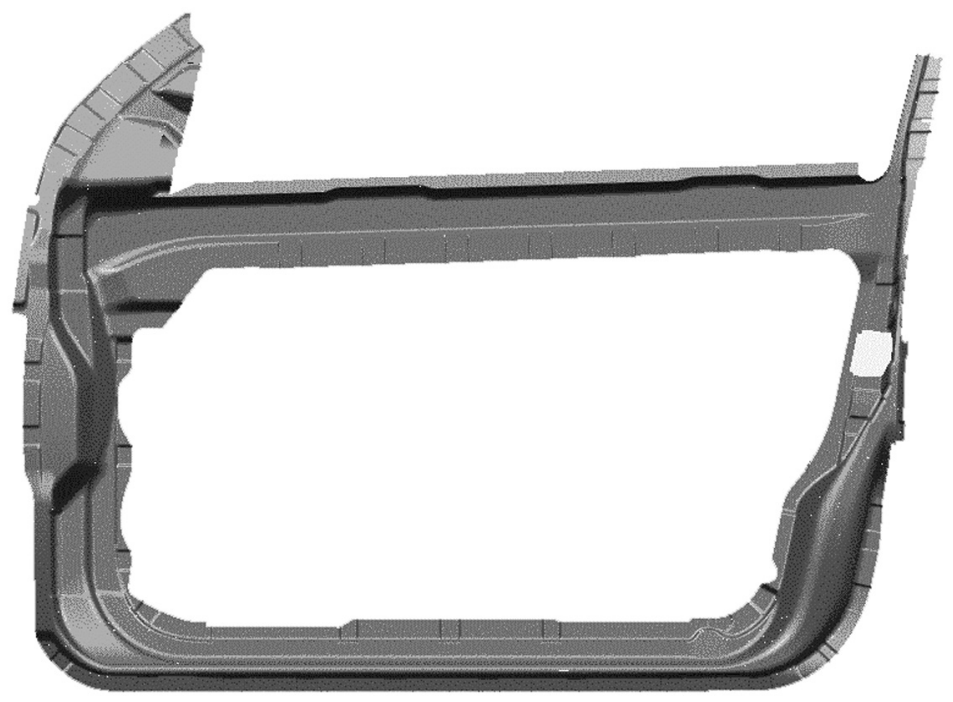

Figura 2: Reforço interno da porta dianteira esquerda. 
Após as coletas de dados na fase de orientação, a fase de informação foi usada para mensurarmos o consumo de matéria-prima indicado semanalmente conforme programa de produção e planejamento da liberação de entrega da matéria-prima para o cálculo do inventário que foi mensurado em peso, em custo e em dias de produção.

Planejamento da fase de especulação. Tendo adquirido a compreensão e a informação, são geradas nesta fase alternativas, fazendo uso de diversas técnicas tanto para partes do problema como para o todo. As alternativas geradas devem ter como conseqüência a eliminação de funções desnecessárias, ou maneiras mais simples de satisfazer a função requerida. Nessa fase, o julgamento será temporariamente suspenso. Especialistas serão consultados. Ao final, será apresentada uma lista de alternativas. As perguntas que devem ser respondidas nesta fase são:

a) O que mais pode executar a mesma função?

b) A que custo?

c) Qual a outra técnica que pode ser aplicada?

d) Qual o custo?

Foram apresentadas três alternativas de forma sistemática. A proposta sugerida será a combinação de alteração de movimentações e mudança no processo de manufatura do item selecionado para o estudo e mostrar todas as variações para efeito de comparação com o estudo anterior.

\section{conceito de Análise do Valor é decompor o produto ou serviço em funções, examinando-} se 0 valor de cada função.

Planejamento da fase de análise. A busca de respostas ao problema anunciado, ou seja, o elemento selecionado para estudo, leva o grupo de trabalho a utilizar sua carga de conhecimento e experiência, na forma como este conhecimento foi construído. Desta forma é possível solucionar o problema, trazendo ganhos na melhoria do desempenho da função e a redução de custos.

Assim, esta fase do modelo tem por função uniformizar os dados, identificando cada parte ou unidade de custo ocorrido no processo produtivo.

A apresentação dos resultados obtidos em forma de relatório ocorrerá nesta fase. Para uma apreciação dos dirigentes, a fim de tornar possível propor mudanças nos processos produtivos para uma nova avaliação nos seus custos.

Nesta fase, o julgamento passará a ter um papel muito importante. Para cada idéia, uma cuidadosa análise irá indicar a resposta adequada do que falta para funcionar e não do por que não funciona. Nessa fase, as idéias são quantificadas e as prioridades estabelecidas. No fim dessa fase, são decididas quais as alternativas que deverão ser estudadas. Ainda nesta fase serão determinadas e comparadas a viabilidade e a conveniência, bem como os custos envolvidos também. As perguntas que devem ser respondidas nesta fase são:

a) É a melhor alternativa?

b) Quão melhor? Pode ser mensurado?

c) Por quê?

d) Quais os custos relacionados?

Nesta fase foi feita a análise do processo atual e das três propostas em relação ao custo da matéria-prima, custos de transportes e custo de manufatura, com objetivo de mensurar valores comparativos entre todas as alternativas. E no final da análise, foi mostrado o peso final do produto para todas as alternativas, mostrando alterações no peso do veículo final.

Fase de planejamento do programa. Nesta fase, é buscada a viabilidade do projeto diretamente nas áreas funcionais, exemplo, logística, manufatura, try-out, compras, finanças etc. e a execução de cada uma delas diretamente com especialistas e fornecedores. É estabelecido um programa de investigação para prover informações técnicas sobre processos de manufatura, logística etc.

Fase de proposta do programa. Nesta fase, deve ser apresentada a proposta junto com o planejamento para implantação, após a implantação da alternativa, deve-se também acompanhar os resultados das possíveis modificações do projeto propostas, devido a condições técnicas ou financeiras.

Planejamento da fase de conclusão. Nesta fase é feita a elaboração do relatório final com todas as variáveis estudadas, em termos de viabilidade, custo, investimento etc. Em casos onde o custo de implementação seja muito grande, ou quando a quantidade total produzida não é clara, deve ser feito um gráfico de equilíbrio. Deve ser apresentado também o impacto dos atrasos das aprovações nas economias obtidas. $\mathrm{Na}$ fase de conclusão, foram abordados todos os resultados encontrados durante o trabalho.

\section{RESULTADOS E DISCUSSÕES}

A seguir são apresentadas as informações obtidas para orientação. 
Informações da caracterização da matéria-prima. A matéria-prima das chapas cortadas que irão formar o tailored blank é composta de bobinas com as mesmas propriedades mecânicas, porém com dimensões diferentes, Figura 3.

- O peso líquido da chapa " 1 " é de $4,570 \mathrm{~kg}$, e após a conformação, o peso líquido da chapa conformada será de $1,960 \mathrm{~kg}$.

- O peso líquido da chapa “2” é de 3,508 kg, e após a con- formação, o peso líquido será de $1,600 \mathrm{~kg}$.

- O peso líquido da chapa " 3 " é de $2,184 \mathrm{~kg}$, e após a conformação, o peso líquido será de $0,880 \mathrm{~kg}$.

Informações da empresa fornecedora da matéria-prima. A usina fornecedora da matéria-prima está a $584 \mathrm{Km}$ da empresa industrializadora do tailored blank e somente a $178 \mathrm{Km}$ da montadora de destino. Porém o tailored blank

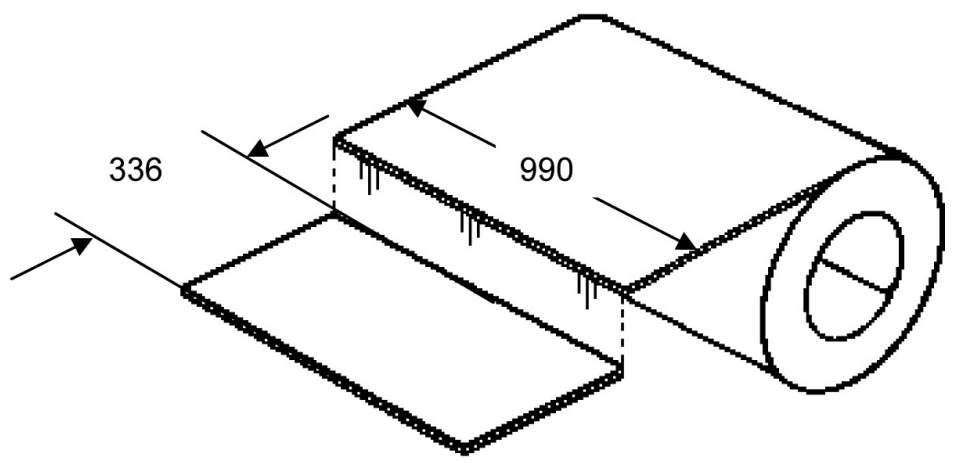

(a)

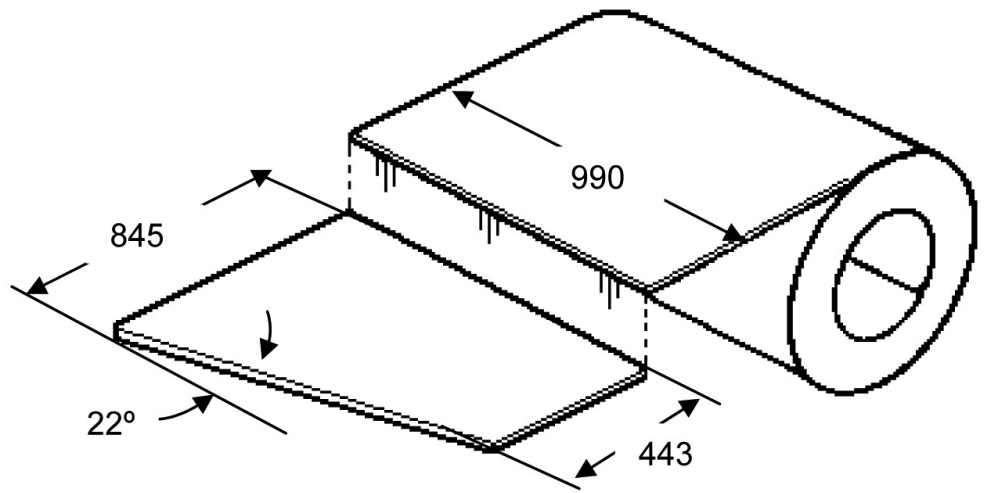

(b)

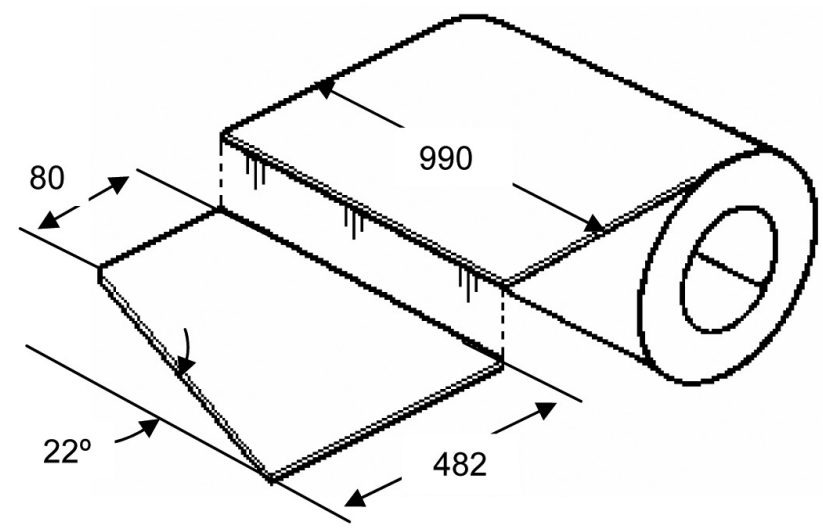

(c)

Figura 3: Dimensões: a) chapa " 1 " de 1,75 mm de espessura, b) chapa " 2 " de 1,50 mm de espessura e c) chapa "3" de 1,00 mm de espessura. 
deverá viajar $408 \mathrm{~km}$ adicionais até a montadora. O ideal seria ter o industrializador entre a montadora e a usina. Estas premissas servem de base de cálculo para o custo de transporte no processo atual.

Informações do custo da matéria-prima. Foi identificado o custo da matéria-prima na Europa, obtido junto à usina fornecedora da Europa que é a ThyssemKrupp Stahl AG, bem como o custo final da bobina aqui no Brasil com as mesmas especificações.

A planilha de custo da matéria-prima na Europa é composta de vários parâmetros, a começar pelo preço base da matéria-prima a um custo de $€ 650,00$ por tonelada. O material base é designado pelo código $\mathrm{DX} 51 \mathrm{D}+\mathrm{Z}$, o mesmo usado aqui no Brasil para designar o material base sem adições.

Ao adicionarmos elementos químicos ao material base para obter as características físicas e mecânicas desejadas, há um custo adicional de $€ 80,00$ por tonelada. Existe também um custo adicional de $€ 9,00$ por tonelada, para o acabamento da superfície (rugosidade). Já para o tratamento de superfície é adicionado um custo de $€ 15,00$ por tonelada.

Neste trabalho, pode-se ainda identificar um custo adicional de $€ 48,00$ por tonelada para as platinas "1" e "2" enquanto que a platina " 3 " terá um custo adicional de $€ 66,00$ por tonelada.

Com o objetivo de proteger a superfície contra agressões

Tabela 1: Custo adicional do pedido.

\begin{tabular}{cc}
\hline Adicional pelo tamanho do lote (ton) & €uro/ton \\
\hline$\geq 20$ ton & base \\
{$[15$ ton; 20 ton[ } & 10,00 \\
{$[10$ ton; 15 ton[ } & 15,00 \\
{$[5$ ton; 10 ton[ } & 20,00 \\
\hline
\end{tabular}

do meio ambiente, usa-se a aplicação de óleo na superfície a um custo de $€ 30,00$ por tonelada.

No uso da norma DIN EN 10143 para as tolerâncias identificadas na norma, tem-se um custo adicional de $€ 15,00$ por tonelada produzida para a platina " 3 " enquanto que o custo adicional para as platinas " 1 " e "2" será de $€ 10,00$ por tonelada.

A usina fornece junto ao produto o certificado de testes a um custo adicional de $€ 5,00$ por tonelada. O custo para a embalagem final da matéria-prima também tem um adicional de $€ 5,00$ por tonelada.

Na Tabela 1, é mostrado o custo adicional pelo tamanho do lote, caso a solicitação seja maior ou igual a vinte toneladas, não haverá adicional algum, já para pedidos inferiores a vinte toneladas pagam-se custos adicionais, em Euros, por tonelada solicitada.

Para o custo da bobina no Brasil, tem-se apenas o custo fechado, onde o pedido mínimo sem adicional é de vinte toneladas. O custo para a bobina com $990 \mathrm{~mm}$ de largura e com espessura de $1,75 \mathrm{~mm}$ é de $\mathrm{R} \$ 1650,00$ por tonelada, já para a bobina com $990 \mathrm{~mm}$ de largura e com espessura de $1,50 \mathrm{~mm}$ é de $\mathrm{R} \$ 1830,00$ por tonelada, enquanto que para a bobina de $990 \mathrm{~mm}$ de largura e com espessura de 1,00 $\mathrm{mm}$ é de $\mathrm{R} \$ 1840,00$ por tonelada.

Informações das movimentações. Na Figura 4, é mostrado o esquema de movimentação da matéria-prima: da bobina e do tailored blank (chapa industrializada).

A primeira movimentação diz respeito ao processo logístico entre a usina fornecedora da bobina, para o industrializador do tailored blank, a uma distância de $584 \mathrm{~km}$.

A segunda movimentação é a do tailored blank, ou seja, é a movimentação entre o industrializador do tailored blank, para a estamparia da fábrica da montadora, a uma distância de $408 \mathrm{~km}$.

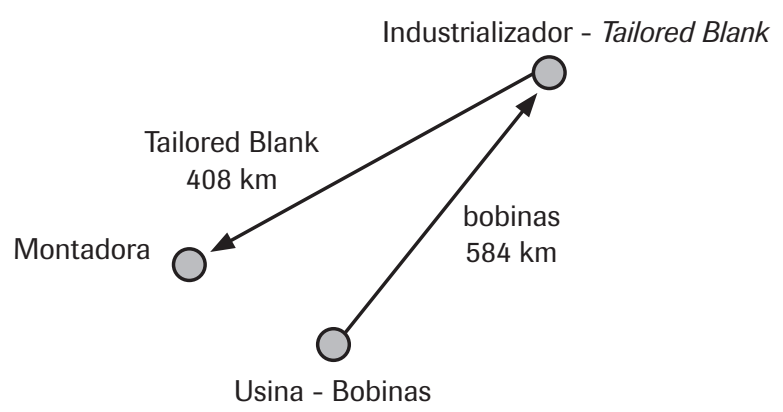

Figura 4: Esquema de movimentação da bobina e do tailored blank. 
Informações de transporte. O transporte é feito por carretas três eixos com capacidade de 25 toneladas, onde o custo da viagem está dividido em custo fixo de $\mathrm{R} \$ 120,00$ por viagem e custo variável de $\mathrm{R} \$ 1,30$ por km rodado.

Propostas de mudança no processo - fase da especulação. Agora qualquer alteração no processo poderá ser mensurada de forma clara e objetiva, pois o resultado da proposta estará baseado nas mesmas premissas levantadas durante todo o processo de orientação e de informação.

Propostas de movimentações. Substituição do industrializador do tailored blank por um industrializador localizado próximo à montadora. Foram identificados dois fornecedores do mesmo grupo, onde o primeiro, está a uma distância de $200 \mathrm{~km}$ da usina fornecedora da bobina, e a $40 \mathrm{~km}$ da montadora. Esse fornecedor realiza apenas o corte da bobina para a transformação em chapas. O segundo fornecedor está a uma distância de 15 $\mathrm{km}$ da montadora e tem condições de fazer a manufatura do tailored blank. A distância entre esses dois fornedores é de $30 \mathrm{~km}$.

Propostas de modificações no produto. A proposta seria a utilização de apenas uma chapa com espessura de $1,75 \mathrm{~mm}$ ou uma chapa intermediária de 1,50 mm.

Consumo de bobina - proposta. As dimensões da nova chapa podem ser vistas na Figura 6, que servirá como base de cálculo para o consumo de bobina.

O peso líquido da chapa com uma só espessura $(1,75$ ou $1,50 \mathrm{~mm}$ ), pode ser calculado baseado na densidade do material, que é de $7,85 \mathrm{~g} / \mathrm{cm}^{3}$ e o volume de $2.184,68 \mathrm{~cm}^{3}$, resultando para uma chapa com espessura de $1,75 \mathrm{~mm}$ um

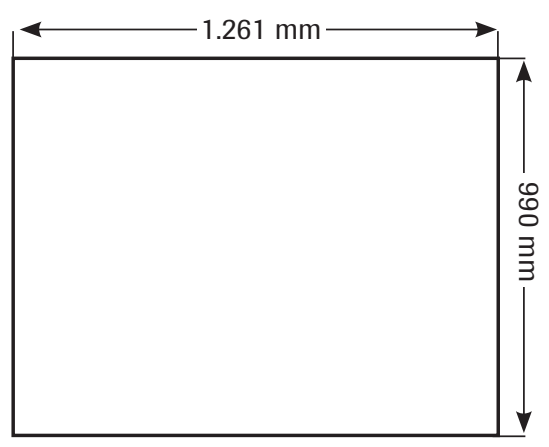

Figura 6: Dimensões da chapa final proposta. peso líquido de 17,150 kg sem perda e 17,321 kg com perda de $1 \%$; já para uma chapa com espessura de $1,50 \mathrm{~mm}$ o peso líquido sem perda no processo resultará em $14,700 \mathrm{~kg}$ e com perda no processo o peso líquido será de $14,847 \mathrm{~kg}$. Para o cálculo do peso consumido por unidade produzida, deve-se multiplicar por dois, por se tratar do item do lado direito e do lado esquerdo.

\section{avendo mais de um produto, seu valor será dado pelo máximo lucro que o mesmo poderá retirar de sua produção.}

Manufatura da chapa - propostas. O custo médio de todo o processo de manufatura da chapa é de $\mathrm{R} \$ 0,75$ por unidade produzida, sem considerar o custo de matéria-prima. As premissas de liberação de solicitação de entrega, o lote de entrega e a perda no processo são os mesmos apresentados no processo atual.

Manufatura do reforço da porta - propostas. O processo de manufatura do reforço da porta será o mesmo do apresentado no processo atual, com duas exceções: a primeira requer um investimento de $\mathrm{R} \$ 120$ mil reais para modificações das ferramentas e a segunda é o aumento na taxa de produção de seis golpes e meio por minuto para quatorze golpes por minuto.

Planejamento de consumo semanal de aço para o ano de 2004 - propostas. Usando-se a proposta da bobina com espessura de $1,75 \mathrm{~mm}$, o consumo de aço no ano de 2004 será de 1.470 toneladas a um custo de $\mathrm{R} \$ 2.426 .469$ no ano. Se optar em usar a bobina com espessura de $1,50 \mathrm{~mm}$, o consumo de aço no ano de 2004 será de 1.261 toneladas a um custo de R\$2.306.788 (SCHRÖDER, 2004).

Discussões do processo atual e propostas - fase da análise. O custo total do tailored blank na planta de destino é formado pelo custo da bobina, mais o custo de transporte da bobina entre a usina e o industrializador, mais o custo de manufatura do tailored blank no industrializador, mais o custo de transporte do tailored blank do industrializador até a planta de destino (SCHRÖDER, 2004).

O tailored blank, na planta de destino, tem um custo final de $\mathrm{R} \$ 80,27$, onde o custo logístico representa $2,20 \%$ do custo total, o custo da matéria-prima representa $63,04 \%$, e o custo de manufatura do tailored blank representa $34,76 \%$. Para uma produção anual de 42.451 veículos, ter-se-á um custo total no ano de R\$3.407.469,60. 
Apresentação da proposta "1". A primeira proposta é apenas a transferência da manufatura do tailored blank. Admitindo-se os mesmos custos de manufatura nos industrializadores ter-se-á apenas um novo custo logístico na composição final do custo do produto, ou seja, a distância entre a usina e o industrializador cai de $584 \mathrm{~km}$ para $200 \mathrm{~km}$, e a distância entre o industrializador e a planta de destino cai de $408 \mathrm{~km}$ para $15 \mathrm{~km}$.

\section{objetivo deste trabalho foi a obtenção de resultados financeiros que possam tornar o produto competitivo.}

O custo total do tailored blank na planta de destino para a proposta " 1 " é formado pelo custo da bobina, mais o custo de transporte da bobina entre a usina e o industrializador, mais o custo de manufatura do tailored blank no industrializador, mais o custo de transporte do tailored blank do industrializador até a planta de destino (SCHRÖDER, 2004).

O tailored blank, na planta de destino, tem um custo final para a proposta "1" de $\mathrm{R} \$ 79,10$, onde o custo logístico representa $0,76 \%$ do custo total, o custo da matéria-prima representa $63,97 \%$ e o custo de manufatura do tailored blank representa $35,27 \%$.

Para uma produção anual de 42.451 veículos, ter-se-á um custo total no ano para a proposta "1" de R\$3.357.780,71.

Uma redução em $66,19 \%$ no custo do transporte, representará um custo evitado de $\mathrm{R} \$ 49.688,89$ ao ano, mostrando uma redução de apenas $1,46 \%$ no custo total do tailored blank na planta de destino.

Apresentação da proposta " 2 ". A segunda proposta é a transferência da manufatura do tailored blank e mudanças no produto, com a escolha da bobina com espessura de $1,75 \mathrm{~mm}$.

O custo total da chapa cortada na planta de destino para a proposta "2" é formado pelo custo da bobina, mais o custo de transporte da bobina entre a usina e o industrializador, mais o custo de manufatura da platina no industrializador, mais o custo de transporte da platina do industrializador até a montadora (SCHRÖDER, 2004).

O tailored blank, na planta de destino, tem um custo final para a proposta " 2 " de $\mathrm{R} \$ 58,87$, onde o custo logístico representa $1,30 \%$ do custo total, o custo da matéria-prima representa $96,15 \%$ e o custo de manufatura do tailored blank representa $2,55 \%$.

Para uma produção anual de 42.451 veículos, ter-se-á um custo total no ano para a proposta "2" de R $2.498 .971,51$.
Comparando a proposta "2" com a situação atual, é verificado um aumento de $11,86 \%$ no custo da matéria-prima, mesmo transportando um peso maior, porém com distâncias menores, o custo logístico de transporte reduziu em $56,61 \%$, e a maior redução no processo foi na manufatura, com uma redução de $94,62 \%$.

Com a possibilidade da implementação da proposta " 2 ", ter-se-á um custo evitado de $\mathrm{R} \$ 908.498,09$ ao ano, porém como há necessidade de investimento para modificações das ferramentas da estamparia em um montante de $\mathrm{R} \$ 120.000,00$, no primeiro ano o custo evitado será de R $\$ 788.498,09$.

Apresentação da proposta “3”. A terceira proposta é a transferência da manufatura do tailored blank e mudanças no produto com a escolha da bobina com espessura de $1,50 \mathrm{~mm}$.

O custo total da chapa cortada na planta de destino para a proposta " 3 " é formado pelo custo da bobina, mais o custo de transporte da bobina entre a usina e o industrializador, mais o custo de manufatura da chapa no industrializador, mais o custo de transporte da chapa do industrializador até a planta de destino (SCHRÖDER, 2004).

O tailored blank, na planta de destino, tem um custo final para a proposta " 3 " de $\mathrm{R} \$ 55,96$, onde o custo logístico representa $1,18 \%$ do custo total, o custo da matéria-prima representa $96,14 \%$ e o custo de manufatura do tailored blank representa $2,68 \%$.

Para uma produção anual de 42.451 veículos, ter-se-á um custo total no ano para a proposta " 3 " de $\mathrm{R} \$ 2.375 .634,37$.

Comparando a proposta " 3 " com a situação atual, é verificado um aumento de 6,32\% no custo da matéria-prima, mesmo transportando um peso maior, porém com distâncias menores, o custo logístico de transporte reduziu em $62,57 \%$, e a maior redução no processo foi novamente na manufatura, com uma redução de 94,62\%.

Com a possibilidade da implementação da proposta "3", ter-se-á um custo evitado de R $\$ 1.031 .835,23$ ao ano, porém como há necessidade de investimento, conforme mostrado na proposta "2", para modificações das ferramentas da estamparia em um montante de $\mathrm{R} \$ 120.000,00$, no primeiro ano o custo evitado será de $\mathrm{R} \$ 911.835,23$.

Discussões após a manufatura por conformação. No processo atual o tailored blank tem um peso líquido de $14,26 \mathrm{~kg}$ e após a conformação, o peso final da peça estampada será de $4,44 \mathrm{~kg}$.

Na proposta "2", com utilização de uma única platina de $1,75 \mathrm{~mm}$, o peso da peça estampada será de $5,37 \mathrm{~kg}$, ou seja, ter-se-á um aumento de 20,87\%, com aumento 
real por carro em $1,85 \mathrm{~kg}$ distribuídos nas duas portas dianteiras.

Na proposta " 3 ", com utilização de uma única platina de $1,50 \mathrm{~mm}$, o peso da peça estampada será de $4,60 \mathrm{~kg}$, ou seja, ter-se-á um aumento de $3,60 \%$, com aumento real por carro em $0,32 \mathrm{~kg}$ distribuídos nas duas portas dianteiras.

Considerações finais. A Tabela 2 mostra a análise da proposta "1". Com alteração do industrializador do tailored blank, haverá uma redução em 56,77\% no custo de transporte da bobina entre a usina e o industrializador e uma redução de 78,54\% no custo do transporte do tailored blank, totalizando uma redução no custo logístico de $66,19 \%$.

Com a implementação da primeira proposta, o custo do tailored blank reduz de $\mathrm{R} \$ 80,27$ por veículo para $\mathrm{R} \$ 79,10$ por veículo, o que representa uma economia de 1,46\%. Para uma produção anual de 42.451 veículos, a economia será de $\mathrm{R} \$ 49.689$ ao final de um ano.

$\mathrm{Na}$ análise da proposta " 2 ", é utilizada a proposta "1" em conjunto com alteração no processo de manufatura da platina, com a eliminação de duas espessuras e mantendo apenas uma espessura de $1,75 \mathrm{~mm}$.

Há uma redução considerável no controle do inventário no industrializador. Atualmente o nível médio semanal do inventário no processo é de $\mathrm{R} \$ 238$ mil, já para a proposta “2" é verificado um inventário médio semanal de R 214 mil, ou seja, uma redução de 10,08\% no custo do inventário.

Quando analisado o inventário em dias de produção, foi verificada uma redução de $21,43 \%$. No processo atual o inventário médio semanal é de 28 dias de produção, contra 22 dias de produção para a proposta "2".
O primeiro ponto negativo identificado durante a análise foi o aumento no custo da matéria-prima de $\mathrm{R} \$ 50,60$ por veículo para $R \$ 56,60$ por veículo, que representa um aumento de $11,86 \%$.

O custo do transporte da bobina teve uma redução de $48,02 \%$ em relação ao processo atual, e para a chapa cortada a redução foi de $67,88 \%$, onde a redução final do custo logístico foi de $56,61 \%$ sobre o processo atual.

A maior redução identificada foi no custo da manufatura, que apresentou uma redução em 94,24\%, caindo de $\mathrm{R} \$ 27,90$ por veículo produzido para $\mathrm{R} \$ 1,50$ por veículo produzido. Esta redução é justificada pela própria complexidade de controle de material e processo de manufatura e a eliminação do processo de soldagem a lazer.

A redução total da proposta "2" será de 26,66\%, ou seja, o custo da chapa cortada por veículo reduz de $\mathrm{R} \$ 80,27$ por veículo, para $R \$ 58,87$ por veículo, tendo uma economia de R\$ 908.498 ao ano para uma produção de 42.451 veículos no ano. Porém como deve haver investimento de R 120.000 no ferramental na modificação do processo, no primeiro ano a redução será de R\$788.498. O investimento terá retorno já no segundo mês de operação.

Em resumo, para a proposta " 2 " houve um aumento de $20,87 \%$ no peso da peça, onde o peso inicial era de $4,44 \mathrm{~kg}$, passando para $5,37 \mathrm{~kg}$, ou seja, cada porta terá um aumento no peso de 926 gramas, que contribuirá para um aumento desprezível no consumo de combustível do veículo.

$\mathrm{Na}$ análise da proposta " 3 ”, com alteração no processo de manufatura da chapa pela eliminação de duas espessuras e mantendo apenas uma espessura de $1,50 \mathrm{~mm}$, é também utilizada a proposta "1".

Tabela 2: Análise financeira - comparativo do processo atual e propostas (SCHRÖDER, 2004).

\begin{tabular}{|c|c|c|c|c|}
\hline \multicolumn{5}{|c|}{ Análise Financeira } \\
\hline RȘ/Veículo & Atual & Prop.1 & Prop.2 & Prop.3 \\
\hline Matéria-Prima & 50,60 & 50,60 & 56,60 & 53,80 \\
\hline Transporte Bobina & 1,0031 & 0,4336 & 0,5214 & 0,4468 \\
\hline Manufatura & 27,90 & 27,90 & 1,50 & 1,50 \\
\hline Transporte Platina/TB & 0,7652 & 0,1642 & 0,2458 & 0,2150 \\
\hline Custo Total & 80,27 & 79,10 & 58,87 & 55,96 \\
\hline Produção Anual & 42.451 & & & \\
\hline Custo Anual & 3.407 .470 & 3.357.781 & 2.498 .972 & 2.375 .634 \\
\hline Redução de Custo & 0 & 49.689 & 908.498 & 1.031 .835 \\
\hline Investimento & 0 & 0 & 120.000 & 120.000 \\
\hline Redução no 1ํAno & 0 & 49.689 & 788.498 & 911.835 \\
\hline
\end{tabular}


Há uma redução considerável no controle do inventário no industrializador, enquanto que o nível médio semanal do inventário no processo atual é de $\mathrm{R} \$ 238$ mil, é verificado um inventário médio semanal na proposta " 3 " de $\mathrm{R} \$ 205$ mil, ou seja, uma redução de $13,87 \%$ no custo do inventário.

Quando analisado o inventário em dias de produção, foi verificada uma redução de $25,00 \%$. No processo atual, o inventário médio semanal é de 28 dias de produção, contra 21 dias de produção para a proposta " 3 ".

Foi identificado também um aumento no custo da matéria-prima de $R \$ 50,60$ por veículo para $R \$ 53,80$ por veículo, que representa um aumento de $6,32 \%$ na matériaprima, porém o aumento foi menor do que identificado na proposta "2".

O custo do transporte da bobina teve uma redução de $55,46 \%$ em relação ao processo atual, e para a chapa a redução foi de $71,90 \%$, onde a redução final do custo logístico foi de $62,57 \%$ sobre o processo atual.

A maior redução identificada ficou também para a redução no custo da manufatura, que representou uma redução em $94,24 \%$, caindo de $R \$ 27,90$ por veículo produzido para $R \$ 1,50$ por veículo produzido, como apresentado na proposta "2".

A redução total da proposta " 3 " será de $30,28 \%$, ou seja, o custo da chapa por veículo reduz de $\mathrm{R} \$ 80,27$ por veículo, para $\mathrm{R} \$ 55,96$ por veículo, tendo uma economia de $\mathrm{R} \$$ 1.031 .835 ao ano para uma produção de 42.451 veículos no ano. Porém, como deve haver também um investimento de $\mathrm{R} \$ 120.000$ no ferramental na modificação do processo, no primeiro ano a redução será de $\mathrm{R} \$ 911.835$. O investimento terá retorno já no segundo mês de operação, da mesma forma que foi identificado no processo " 2 ".

Em resumo, para a proposta " 3 ", houve um aumento de $3,60 \%$ no peso da peça, onde o peso inicial era de $4,44 \mathrm{~kg}$, passando para 4,60 kg, ou seja, cada porta terá um aumento no peso de apenas 160 gramas, e como houve uma redução na espessura é necessário realizar testes de impacto para verificação do item de segurança.

Com os custos do aço na Europa, pôde ser identificado um custo superior a $85 \%$ em relação ao mesmo aço comprado aqui no Brasil, justificando mais uma vez o desenvolvimento tecnológico em busca de alternativas para o atendimento da produção Européia.

\section{CONCLUSÕES}

Neste trabalho, foi utilizada a metodologia da Análise do Valor como forma de chegar a um resultado sistemático em análise de processo e custo. Durante o estudo, foram identificadas duas linhas com o objetivo de modificação, a primeira que é a movimentação, ou seja, diminuição nas distâncias entre os processos de manufatura, a segunda diz respeito à modificação do produto, visando uma otimização no processo produtivo e conseqüentemente uma redução no custo do produto. Já a terceira proposta é a transferência da manufatura do tailored blank e mudanças no produto.

O presente estudo foi feito em uma peça de tamanho médio e isolada que financeiramente mostrou uma inviabilidade econômica que é justificada pelo porte da mesma. A experiência mostra que já para peças de maior porte, como por exemplo a lateral de um veículo e assoalhos, que utilizam o mesmo princípio tecnológico, a operação se torna economicamente viável, pois nesse caso a redução no custo da matéria-prima com a utilização do tailored blank é superior ao custo de manufatura, visto que o aproveitamento de material se torna significante.

A primeira proposta é a única que não altera o processo de produção, mas apenas o conceito logístico, ou seja, pode ser implantado sem fazer qualquer tipo de análise do produto.

$\mathrm{Na}$ segunda proposta, além da alteração das movimentações, há uma alteração no processo de manufatura. Nessa proposta há ainda um aumento de peso no veículo na ordem de 1.852 gramas, o que, pela experiência, não afetará de forma significativa o consumo de combustível.

Para a terceira proposta, além da alteração das movimentações, há uma alteração no processo de manufatura, onde o aumento do peso do veículo é menor que na proposta " 2 ", em torno de 320 gramas, porém há uma região onde a espessura será inferior ao projeto inicial, havendo assim uma necessidade de análise de resistência.

A importância da análise do inventário de forma sistêmica incorre diretamente na informação do custo de oportunidade, que é o valor do benefício que se deixa de ganhar quando, no processo decisório, se toma um caminho em detrimento de outro.

\section{Artigo recebido em 07/02/2007 Aprovado para publicação em 02/01/2008}




\section{REFERÊNCIAS}

ABEAV - Associação Brasileira de Engenharia e Análise do Valor, 1984.

BIO, S. R. Sistemas de Informações: Um Enfoque Gerencial. São paulo: Atlas, 1991.

CHEAH, C. Y. J. AND TING, S. K. Appraisal of value engineering in construction in Southeast Asia. International Journal of Project Management, v. 23, n. 2, p. 151-158, 2005.

CSILLAG, J. M. Análise do Valor: metodologia do valor: Engenharia do valor, gerenciamento do valor, redução de custos, racionalização administrativa. 4. ed. São Paulo: Atlas, 303 p., 1995.

DI PIETRO, F. A. Laser blank welding and stamping of sheet metal parts. Proceeding of ICALEO, p. 621-626, 1992.

FIRJAN. Qualidade \& Produtividade e sua relação com os sistemas de gestão. <www.firjan. org.br/notas/media/paper1.pdf>. 2002
FLEMING, Q. W.; KOPPELMAN, J. M. Earned Value Project Management. 2nd edition, Newton Square: Project Management Institute, 2002.

FORGART, D. W.; BLACKSTONE, J. H.; HOFFMANN, T. R. Production and Inventory Management, 2. ed. Cincinati: South-Western Publishing Company, 1991.

HAMILTON, A. Considering value during early project development: a product case study. International Journal of Project Management, v. 20, p. 131-136, 2002.

LEONE, G. S. G. Custos: Planejamento, Implantação e Controle. São Paulo: Atlas, 2000.

Miles, L. D. Techniques of Value Analysis and engineering. Mcgraw Hill, 2. ed., 1972

NAKAGAWA, M. Gestão Estratégica de Custos: Conceitos, Sistemas e Implementação. São Paulo: Atlas, 1991.
PEREIRA F. R. R. Análise do valor. Processo de melhoria contínua. 1. ed. São Paulo: Nobel, 1994

PETEnAte, A. J. Utilização do Método de Taguchi na Redução dos Custos de Projetos. Dissertação de mestrado pela Universidade Estadual de Campinas, 2001.

SCHRÖDER, R. P. Análise do Valor na Conformação do Tailored Blank: Um estudo de caso na indústria automobilística. Dissertação de mestrado PGMec/UFPR, 2004.

VARGAS, R. V. Análise do Valor Agregado em Projetos. Editora Brasport, 2002.

ZENS, G. J. Purchasing and the Management of Materials. 7th ed. John Wiley \& Sons, Inc, 1994

\section{AGRADECIMENTOS}

Os autores agradecem a empresa Volkswagen Audi pela liberação para o levantamento das informações do presente trabalho.

\section{SOBRE OS AUTORES}

Ronnie Peterson Schröder

Volkswagen do Brasil Ltda.

End.: Via Anchieta, km 23,5, S.B. do Campo - SP - CEP 09823-990

Tel./Fax: (11) 4347-5208

E-mail: ronnie.schroder@volkswagen.com.br

\section{Paulo Victor Prestes Marcondes}

Universidade Federal do Paraná - UFPR / DEMEC

End.: Caixa Postal 19011 - Curitiba - PR - CEP 81531-990

Tel.: (41) 3361-3431 / Fax: 3361-3129

E-mail:marcondes@ufpr.br 